\title{
Anna Hollsten
}

\section{Tunnustuksellinen runous salonkikelpoiseksi!}

Sitä mukaa kuin tunnustuksellinen puhe on vallannut yhä enemmän alaa juorulehdissä, tosi-tv:ssä ja internetissä, akateeminen kiinnostus sekä sen uusiin että perinteisempiin muotoihin on kasvanut. Esimerkiksi Heikki Kujansivun ja Laura Saarenmaan toimittama artikkelikokoelma Tunnustus ja todistus. Näkökulmia kahteen elämän esittämisen tapaan (2007) avaa näkymiä tunnustukselliseen puheeseen Augustinuksen Tunnustuksista internetin tarinoihin. Tunnustuksellisen puheen ja kirjoittamisen taustalla on pitkä uskonnollisen tunnustuksen ja oikeuden tunnustuskäytäntöjen perinne. Nykyinen tunnustuskulttuuri on kuitenkin välittömämmin kytköksissä 1960-luvulta alkaneisiin yhteiskunnallisiin ilmiöihin, jotka ovat murentaneet yksityisen ja julkisen rajaa: psykoterapian yleistymisen myötä avoimuuden ja totuudenmukaisuuden ihanteet levisivät laajasti kulttuuriin, nouseva naisliike korosti yksityiselämän poliittisuutta, ja televisio sekä kasvava ajanvietelehdistö ruokkivat uudenlaista mediajulkisuutta. ${ }^{1}$

Olen tutkinut suomalaista 1960-1970-lukujen tunnustuksellista runoutta ja huomannut, että siinä missä angloamerikkalaisessa kirjallisuudentutkimuksessa ja -historiassa tunnustuksellisuus näyttäytyy ennen kaikkea runouden lajina, suomalaisissa kirjallisuudenhistorioissa se on mielletty ensisijaisesti proosan lajiksi. ${ }^{2}$ Kuten katsaukseni osoittaa, tunnustuksellinen runous ei kuitenkaan ollut harvinainen laji runoudessamme 1960-1970-luvuilla. Voikin kysyä, missä määrin tunnustuksellisen runouden käsitteen vähäinen käyttö johtuu lajin heikosta arvostuksesta. Niin kriitikot, tutkijat kuin runoilijat itse ovat suhtautuneet ja suhtautuvat edelleen tunnustukselliseen runouteen vähättelevästi. Tunnustuksellinen runous on usein leimattu pelkäksi terapiakirjoitteluksi ja/tai vastenmieliseksi narsismiksi. Vaikka monet tunnustukselliset runoilijat ovat tosiasiallisesti miehiä, tunnustuksellista runoutta on pidetty naisten lajina, mikä ei ole ollut omiaan parantamaan lajin arvostusta.

Ehdotan, että tunnustukselliseen runouteen liitetyt kielteiset mielikuvat heitettäisiin romukoppaan niin, että termiä voisi käyttää ei-arvottavana historiallisena lajikäsitteenä. Perustelen ehdotustani uusilla näkemyksillä tunnustuksellisesta runoudesta. Etenkin Jo Gillin tutkimukset Anne Sextonin ja Ted Hughesin runoudesta ovat monipuolistaneet ja jopa kumonneet aikaisempia näkemyksiä tästä lajista (ks. Gill 2006b; 2007). Väitän, että uuden tutkimuksen valossa tunnustuksellinen runous on vähintäänkin yhtä salonkikelpoinen käsite kuin sen rinnalle luodut autofiktiivisen ja omaelämäkerrallisen runouden käsitteet, joihin palaan lopuksi. 


\section{Mitä on tunnustuksellinen runous?}

Angloamerikkalaisessa kirjallisuudentutkimuksessa ja kritiikissä tunnustuksellisesta runoudesta (confessional poetry) on puhuttu vuodesta 1959 alkaen, jolloin kriitikko M. L. Rosenthal käytti termiä Robert Lowellin samana vuonna ilmestyneen Life Studies -kokoelman arvostelussa (Gill 2007, 10). Tunnustuksellinen runous voidaan määritellä runoudeksi, joka nostaa näkyvästi esille runoilijan elämäkerrallisia aineksia. Se on useimmiten kirjoitettu minä-muodossa, ja kun usein vielä mainitaan runoilijaan liittyviä nimiä ja paikkoja, syntyy vaikutelma runoudesta, jossa runoilija tekee avoimesti tiliä omista tunteistaan ja kokemuksistaan. (Gregory 2006, 34.) Tunnustuksellisella runoudella ei ole vakiintunutta tyyliä tai muotoa, mutta sille ominaisina piirteinä on pidetty kertovuutta, muodon avoimuutta ja pyrkimystä puheenomaiseen kieleen (Phillips 1973, 12-13, 16-17). Sisällöltään tunnustuksellinen runous on painottunut erityisesti erilaisiin häpeällisiksi koettuihin ilmiöihin, kuten mielisairauteen, perheen ongelmiin, lapsuuden traumoihin ja seksuaalisuuteen (Gregory 2006, 34). Varhaisessa tutkimuksessa tunnustuksellista runoutta on luonnehdittu katarttiseksi; häpeällisten asioiden julkituomista on pidetty terapeuttisena, helpotusta tuovana ja lähes pakonomaisena toimintana (Gill 2006b, 69).

Varhaiset tunnustuksellisen runouden kriitikot ja tutkijat painottivat lajin subjektiivisuutta, autenttisuutta ja totuudellisuutta. Käsitys eheästä, tekstinulkoisesta minästä on kuitenkin vähitellen problematisoitunut. Nykyisin lähdetään siitä, että tunnustuksellisuus on ritualisoitunut tekniikka niin minän kuin totuuden tuottamiselle. Moderni tunnustuksellinen runous ei ole irrallaan paradigmanmuutoksesta, vaan sille on tyypillistä tietoisuus lajin konventioista, niiden problematisointi ja niillä leikkiminen. (Gill 2006a, 3-4, 7-8.) Tunnustuksellisen runon minän tuotettua luonnetta sekä minän suhdetta runoilijan julkisiin rooleihin on kuvattu performanssin ja performatiivisuuden käsitteiden avulla (ks. esim. Gill 2007, 169-170; Hollsten 2012, 11-14). Kun tunnustuksellisuutta tarkastelee performanssina, runoilijan julkisuus ja runoilijan suhde yleisöön korostuvat. Raja runoilijan ja yleisön yhteistyöhön perustuvan vuorovaikutuksen ja hyväksikäytön välillä voi olla häilyvä. Runoilijan suosio voi johtaa helposti siihen, että hänestä tulee paitsi yleisön lemmikki myös yleisön odotusten vanki. (Gill 2007, 169, 121, 131.)

\section{Tunnustuksellinen runous 1960 - ja 1970 -luvun suomalaisessa kirjallisuudessa}

Suomessa ilmestyi 1960-1970-luvuilla runsaasti runoutta, jota voi luonnehtia tunnustukselliseksi. Kyse ei ole yhtenäisestä virtauksesta: tunnustukselliselle runoudelle ominaisia muotopiirteitä, aiheita, motiiveja ja teemoja esiintyi heterogeenisella runoilijajoukolla. Suorasta vaikutussuhteesta angloamerikkalaisen ja suomalaisen tunnustuk- 
sellisen runouden välillä ei voi myöskään puhua. Kirjallisuuslehtien, kuten Parnasson ja Aikalaisen, perusteella näyttää siltä, ettei 1960- ja 1970-luvun Suomessa keskusteltu angloamerikkalaisesta tunnustuksellisesta runoudesta lukuun ottamatta Allen Ginsbergin runoutta. Ginsbergiäkään ei tunnettu Suomessa niinkään tunnustuksellisena runoilijana kuin beat-runoilijana. ${ }^{3}$

Silloin kun suomalaisissa kirjallisuudenhistorioissa on puhuttu 1960- ja 1970luvun tunnustuksellisesta runoudesta, ilmiö on liitetty ajan naisliikkeeseen tai väljemmin naisemansipaatioon (ks. Enwald 1999, 203-204; Warburton 1984, 407). Tunnustuksellisen runouden ja naisliikkeen yhteys näkyy Suomessa erityisesti suomenruotsalaisessa kirjallisuudessa. Toisen aallon feminismin keskeisiin hahmoihin kuuluva Carita Nyström kirjoitti kokoelmassaan Ur moderlivet (1978) äitiydestä omien kokemustensa pohjalta. Kirjallisuutemme tunnetuin esimerkki feministisesti sävyttyvästä tunnustuksellisesta runoudesta lienee Märta Tikkasen Århundradets kärlekssaga (1978). Kuten muun muassa Eeva Kilven lyriikka osoittaa, feministinen tunnustuksellinen runous ei ollut tuntematon ilmiö suomenkielisessäkään kirjallisuudessa.

Tunnustuksellisen runouden suosikkiaiheita ovat mielenterveysongelmat. Suomessa aihe esiintyy läpikäyvästi vähän tunnetun suomenruotsalaisen Inger Granholmin kokoelmassa I deras hus (1978). Maila Pylkkönen on kuvannut Nikkilän psykiatrisen sairaalan elämää Muistista-teoksensa (1972) runossa "Mielisairaalan pihalla". Pekka Kejosen Hotelli Huminan lauluja -kokoelman (1972) nimi kertoo jo sen sisällöstä: Hotelli Humina oli liikanimi Kuopion lähistöllä sijaitsevalle Harjamäen psykiatriselle sairaalalle. Aihe, joka saa myös toistuvasti tunnustuksellisia muotoja 1960- ja 1970 -luvun runoudessamme, on läheisen ihmisen kuolema. Anja Vammelvuon Lintu pieni (1970) on ilmestynyt pian runoilijan puolison, Jarno Pennasen, kuoleman jälkeen. Pertti Niemisen kokoelmassa Huomisella vielä omat huolensa muistellaan lapsena kuollutta siskoa (1979).

Ajatus tunnustuksellisen runon itserefleksiivisyydestä taikka minän tuotetusta, performatiivisesta luonteesta sopii lajin suomalaisiin 1960- ja 1970-luvun edustajiin paremmin kuin hyvin, kuten Saarikosken Katselen Stalinin pään yli ulos (1969) osoittaa. Vaikka Saarikosken omaelämäkerrallista proosaa on luonnehdittu tunnustukselliseksi, termiä on käytetty säästeliäästi hänen runoutensa yhteydessä. ${ }^{4}$ Katselen Stalinin pään yli ulos -teosta voidaan kuitenkin lukea modernina tunnustuksellisena runoutena, joka tietoisesti leikkii lajin konventioilla. Tunnustuksellisen runouden oletettu totuudellisuus ja uskonnollisen tunnustuksen perinne parodioituvat, kun Islannissa vieraileva puhuja muistelee ensimmäistä käyntiän Reykjavikissa. Muistelujakso alkaa oireellisesti säkeellä "[s]illoin jo valehtelin" (Saarikoski 1969, 44). Puhuja oli valehdellut isäntäperheelleen olevansa katolinen sillä seurauksella, että katolisen seurakunnan pappi vei hänet messuun. Puhuja kieltäytyi ripistä, koska ei osannut tunnustaa syntejään englanniksi, "mutta pappi sanoi ymmärtävänsä mistä on kysymys/ ja antoi synninpäästön” (Saari- 
koski 1969, 44-45). Myös ajatus tunnustuksellisesta performanssista istuu Saarikosken teokseen. Puhujan jatkuva selonteko omasta juomisestaan voidaan tulkita performanssina, joka teoksen ilmestymisaikana toisti ja vahvisti median antamaa kuvaa runoilijasta. Puhujan häpeämätön asenne omaa juomistaan kohtaan kyseenalaistaa kiinnostavasti perinteiseen tunnustuksellisuuteen liittyvää häpeän tunnetta. Näyttää siltä, että moderni itserefleksiivinen tunnustuksellinen runous tekee eroa perinteestä julistamalla, ettei intiimien asioiden julkituomisessa ole mitään häpeällistä.

1960- ja 1970-luvun suomalaisesta kirjallisuudesta puhuttaessa tunnustuskirjallisuudella on tarkoitettu yleisesti omaelämäkerrallisia teoksia riippumatta siitä, käsittelevätkö ne tunnustukselle ominaisia kysymyksiä vai eivät (ks. Koivisto 2011, 21). Tämän mukaisesti tunnustukselliseksi runoudeksi voisi nimetä kaikki runot, jotka luovat vaikutelman omaelämäkerrallisuudesta. Käsite kuitenkin menettää kuvausvoimansa, jos se irrotetaan kokonaan tunnustuksellisuuden ydinkysymyksistä. Lajimääre ei esimerkiksi sovi kaikkiin perheen ja suvun historiaa kuvaaviin omaelämäkerrallisiin runoteoksiin, joita ilmestyi runsaasti 1960- ja 1970-luvulla. Muun muassa Lars Huldén, Viljo Kajava, Anja Samooja ja Arvo Turtiainen ovat kirjoittaneet sukunsa vaiheista. He ovat henkilö- ja sukuhistoriansa kautta peilanneet kansakunnan vaiheita ja yhteiskunnallisia muutoksia, kuten sotia ja 1960-luvun rakennemuutosta. Heidän näkökulmansa omaan menneeseen on siten pikemminkin historiallinen ja poliittinen kuin yksilöpsykologinen.

\section{Omaelämäkerrallinen ja autofiktiivinen runous}

Vaikka käsitykset tunnustuksellisesta runoudesta ovat muuttuneet, termillä on monien mielestä edelleen kielteinen leima. Rinnalle on noussut neutraalimpana pidettyjä vaihtoehtoja, kuten omaelämäkerrallinen runous (Gregory 2006, 35) tai viime aikoina autofiktiivinen runous, jota on Suomessa käyttänyt esimerkiksi Outi Oja (2012, 116-119; 2013, 132) luonnehtiessaan Turun runoliikkeeseen kuuluvien runoilijoiden tuotantoa. Autofiktiivisen runouden käsite on johdettu analogisesti autofiktiivisen romaanin käsitteestä. Vaikka Serge Doubrovskyn vuonna 1977 lanseeraama autofiktion $k_{a ̈ s i t e}{ }^{5}$ on alun perin viitannut romaanikirjallisuuteen, ei sen käyttö runouden yhteydessä ole kaukaa haettua. Doubrovskyn Le Livre brisé-romaania (1989) analysoinut Armine Kotin Mortimer $(1993,86)$ on nimittäin verrannut autofiktiivisen romaanin kirjailijaa muistuttavaa päähenkilöä lyyrisen rakkausrunon minään eli ajatukseen siitä, ettei runo representoi pelkästään runoilijaa ja hänen todellista elämäänsä tai hänen luomansa kirjallisen hahmon elämää vaan jotakin siltä väliltä.

Pitäisikö sitten tunnustuksellisen runouden termistä luopua ja siirtyä muodikkaampaan autofiktiivisen runouden käsitteeseen? Mielestäni ei, koska silloin unohdetaan käsitteiden historiallisuus ja heitetään helposti lapsi pesuveden mukana. Olisi anakronistista kutsua autofiktiiviseksi runoutta, joka on ilmestynyt ennen Doubrovskyn autofiktio-keskustelua. Sen sijaan käsite sopii kuvaamaan keskelle autofiktion buumia 
syntynyttä nykyrunoutta, joskin vaarana on silloinkin, että käsite häivyttää nykyrunouden yhteyden aikaisempaan perinteeseen. ${ }^{6}$ Tunnustuksellisen runouden käsitteellä on kuitenkin rajoituksensa, joten sekään ei sovellu yleiskäsitteeksi. Suomalaisessa 1960- ja 1970-luvun kirjallisuudessa on runoutta, jota sisältönsä puolesta on vaikea mieltää tunnustukselliseksi, vaikka muodon puolesta runo noudattaisi tunnustuksellisen runon repertuaaria. Mikäli tällaisissa tapauksissa halutaan korostaa runon omaelämäkerrallisia aineksia, voidaan puhua omaelämäkerrallisesta runoudesta.

\section{Viitteet}

${ }^{1}$ Ks. esim. Jallinoja (2000). Mediakulttuurin muutoksista 1960- ja 1970-luvun Suomessa, ks. myös Saarenmaa (2010). Julkisuuskulttuurin muutoksen vaikutuksesta tunnustuksellisuuden kasvavaan suosioon, ks. esim. Makkonen (1995, 111-112) ja Kujansivu \& Saarenmaa (2007, 9-10).

${ }^{2}$ Kai Laitisen $(1981,611)$ Suomen kirjallisuuden historiassa käsitellään lyhyesti tunnustusproosaa. Suomen kirjallisuushistorian 3. osassa tunnustuksellinen runous mainitaan lyhyesti Liisa Enwaldin (1999, 203-204) kirjoittamassa luvussa "Naiskirjallisuus". Finlands svenska litteraturhistoria -teoksessa ei puhuta tunnustuksellisesta runoudesta. Märta Tikkanen luetaan kyllä tunnustajien joukkoon, mutta hänen tunnustuksellinen runoteoksensa Århundradets kärlekssaga (1978) on luokiteltu aforismisarjaksi (Söderling 2000, 203). Thomas Warburtonin $(1984,407)$ teoksessa Åttio år finlandssvensk litteratur Tikkasen teos luokitellaan sen sijaan tunnustukselliseksi runoksi (bekännelsedikt). Teoksessa ei kuitenkaan ole muita mainintoja lajista.

${ }^{3}$ Ginsbergin runouden vaikutus suomalaisen beat- ja underground-runouden syntyyn oli huomattava ja näkyy esimerkiksi Anselm Hollon, Markku Innon, Pekka Kejosen ja Kosti Sirosen tuotannossa.

${ }^{4}$ Saarikosken omaelämäkerrallisen proosan tunnustuksellisuudesta ks. esim. Hosiaisluoma (1998, 203-204), Laitinen (1981, 578) ja Riikonen (1992, 50-56). Katselen Stalinin pään yli ulos-kokoelman aikalaisarvosteluissa on yksittäisiä mainintoja tunnustuksellisuudesta (ks. esim. Vainionpää 1969). ${ }^{5}$ Autofiktion käsitteestä, ks. esim. Ireland (1993, 43-45).

${ }^{6}$ Ojan $(2012,116-119 ; 2013,129,132)$ luonnehdinta turkulaisrunoilijoiden runoudesta välttää mainitun vaaran sikäli, että Oja nostaa esille runoilijoiden yhteydet beat-runouteen ja tunnustukselliseen runouteen.

\section{Lähteet}

Enwald, Liisa 1999. Naiskirjallisuus. Pertti Lassila (toim.), Suomen kirjallisuushistoria 3. Rintamakirjeistä tietoverkkoihin. Helsinki: SKS, 199-211.

Gill, Jo 2006a. Introduction. Jo Gill (ed.), Modern Confessional Writing. New Critical Essays. London: Routledge, 1-10.

Gill, Jo 2006b. "Your Story. My Story". Confessional Writing and the Case of Birthday Letters. Jo Gill (ed.), Modern Confessional Writing. London: Routledge, 67-83.

Gill, Jo 2007. Anne Sexton's Confessional Poetics. Gainesville et al.: University Press of Florida.

Gregory, Elizabeth 2006. Confessing the Body. Plath, Sexton, Berryman, Lowell, Ginsberg and the Gendered Poetics of the 'Real'. Jo Gill (ed.), Modern Confessional Writing. New Critical Essays. London: Routledge, 33-49. 
Hollsten, Anna 2012. Tapaus Kejonen. Esimerkki 1960- ja 1970-luvun tunnustuskirjallisuuden ja julkisuuden suhteesta. Avain 1/2012, 3-18.

Hosiaisluoma, Yrjö 1998. Euroopan reunalla, kosken korvalla. Jumalten narri Pentti Saarikoski. Helsinki: Like.

Ireland, John 1993. "The Fact is that Writing is a Profoundly Immoral Act.” An Interview with Serge Doubrovsky. Genre XXVI (Spring), 43-49.

Jallinoja, Riitta 2000. Ylilatautunut yksityiselämä. Tommi Hoikkala \& J. P. Roos (toim.), 2000-luvun elämä. Sosiologisia teorioita vuosituhannen vaihteesta. Helsinki: Gaudeamus, 172-186.

Koivisto, Päivi 2011. Elämästä autofiktioksi. Lajitradition jäljillä Pirkko Saision romaanisarjassa Pienin yhteinen jaettava, Vastavalo ja Punainen erokirja. Helsinki: Helsingin yliopisto.

Kujansivu, Heikki \& Laura Saarenmaa 2007. Tunnustus ja todistus omaelämäkerrallisen esittämisen muotoina. Heikki Kujansivu \& Laura Saarenmaa (toim.), Tunnustus ja todistus. Näkökulmia kahteen elämän esittämisen tapaan. Helsinki: Gaudeamus, 7-20.

Laitinen, Kai 1981. Suomen kirjallisuuden historia. Helsinki: Otava.

Makkonen, Anna 1995. Pamfletista tunnustukseen: lajimurros 1960- ja 1970-luvulla. Esimerkkinä Christer Kihlmanin Ihminen joka järkkyi. Markku Ihonen \& Yrjö Varpio (toim.), Helmi, simpukka, joki. Kirjallisuushistoria tänään. Helsinki: SKS, 102-114.

Mortimer, Armine Kotin 1993. The Death of Autobiogpraphy in Doubrovsky's Broken Novel. An Interview with Serge Doubrovsky. Genre XXVI (Spring), 85-108.

Oja, Outi 2012. From Autofictive Poetry to the New Romanticism. The Guises of Finnish Poetry in the 1990s and 2000s. Leena Kirstinä (ed.), Nodes of Contemporary Finnish Literature. Helsinki: SKS, 112-135.

Oja, Outi 2013. Runo nousee lamasta. Mika Hallila et al. (toim.), Suomen nykykirjallisuus 1. Lajeja, poetiikkaa. Helsinki: SKS, 127-145.

Phillips, Robert 1973. The Confessional Poets. Carbondale: Southern Illinois University Press.

Riikonen, Hannu K. 1992. Töitä ja päiviä. Tutkielmia Pentti Saarikosken myöhäistuotannosta. Helsinki: SKS.

Saarenmaa, Laura 2010. Intiimin äänet. Julkisuuskulttuurin muutos suomalaisissa ajanvietelehdissä 1961-1975. Tampere: Tampere University Press.

Saarikoski, Pentti 1969. Katselen Stalinin pään yli ulos. Helsinki: Otava.

Söderling, Trygve 2000. Sextio- och sjuttiotalsprosa. Michel Ekman (ed.), Finlands svenska litteraturhistoria II. Helsingfors: Svenska litteratursällskapet i Finland. Stockholm: Bokförlaget Atlantis, 287-302.

Vainionpää, Marja-Leena 1969. Osallistujat menevät itseensä. [Arvostelu: Saarikoski, Katselen Stalinin pään yli ulos \& neljä muuta kokoelmaa]. Aamulehti 21.12.1969.

Warburton, Thomas 1984. Attio år finlandssvensk litteratur. Helsingfors: Schildts. 